\title{
LA MEMORIA COMO RELATO Y REPRESENTACIÓN DE LA ESCISIÓN DE LA INFANCIA FRENTE AL UNIVERSO ADULTO. UN aCerCamiento a la POESía de Yolanda PANTin
}

\author{
MEMORY AS NARRATIVE AND REPRESENTATION OF THE RUPTURE \\ OF INFANCY WHEN CONFRONTED BY THE ADULT UNIVERSE. AN \\ APPROACH TO THE POETRY OF YOLANDA PANTIN
}

\section{Kira Elena Morales Zamora ${ }^{1}$}

\section{RESUMEN}

De acuerdo con Michel Foucault, toda memoria debe entenderse necesariamente como una "recreación" en cuanto re-produce algo que ya no está. Desde esta perspectiva, una aproximación a los textos: Casa o lobo y de "Los hornos" de La épica del padre de Yolanda Pantin permite concebir el recuerdo como imágenes que se articulan gracias a un intento por reconstruir un relato en el que lo recordado depende necesariamente de la percepción del presente, desde donde el sujeto lírico recuerda. Así, la voz poética construye el relato de su identidad desde la conciencia de que el origen es problematizado desde el momento que se reconocen las discontinuidades que lo conforman. Además, en los versos de esta autora se pone de manifiesto que entre el universo de la infancia y el de la adultez existe una escisión insalvable que revela que los ojos del adulto sólo pueden reconstruir la infancia bajo la conciencia de lo que no se puede volver a ser.

Palabras clave: Memoria, relato, origen, discontinuidad, infancia.

\section{ABSTRACT}

According to Michel Foucault, memory must be necessarily understood as a "re-elaboration" as it reproduces something that is not there anymore. From this perspective, an approach to the texts Casa o Lobo and "Los hornos" from the book Épica del padre by Yolanda Pantin permits us to conceive remembrance as the articulation of images thanks to an attempt of reconstructing a narrative in which what is remembered depends necessarily on the perception of the present from which the poetic subject remembers. Therefore, the poetic voice constructs the narrative of its identity from the consciousness that the origin is questioned from the moment the discontinuities that construct it

\footnotetext{
${ }^{1}$ Magíster en Filología Hispánica. Universidad Simón Bolívar. Caracas, Venezuela. E-mail: kiraelena@usb.ve / kiraelenamorales@hotmail.com
} 
are recognized. Moreover, in this author's verse, it becomes apparent that between the universes of childhood and adulthood, there is an insurmountable rupture revealing that the adult's eyes can only reconstruct childhood under the consciousness of what we may never be again.

Keywords: Memory, narrative, origin, discontinuity, childhood.

Recibido: 02.07.2009. Aprobado: 12.03.2010.

I

ODA memoria es necesariamente una recreación en cuanto reproduce algo que ha ocurrido en un tiempo pasado. En este sentido, cabe pensar la memoria como un relato de aquello que ya no está. Es decir, como narración que se erige sobre algo que se encuentra ausente.

La tesis central de la monumental obra de Ricoeur, Tiempo y relato, es que "el tiempo deviene tiempo humano en la medida en que es articulado de manera narrativa; a la inversa, el relato es significativo en la medida en que dibuja los trazos de la experiencia temporal". Aquí el tiempo, y particularmente el pasado humano, no son reducidos al relato mismo, pero la experiencia narrativa es vista como constituyendo nuestro único e indirecto modo de acceso al tiempo histórico (Brauer, 2002: 44).

La articulación narrativa funciona, entonces, como la única forma de acceder al pasado, a aquello que ya no está pero que es fundamental para la producción de la identidad. Explica Ricoeur que la memoria personal posee tres características fundamentales: en primer lugar es singular, nadie puede tener los recuerdos de otro; seguidamente, la memoria es el presente del pasado, es decir, recordar es traer al presente algo que está ausente; y por último, gracias a la memoria es que el pasado y el futuro se relacionan. La primera cualidad es la que hace que la memoria constituya "por sí sola un criterio de identidad personal" (Ricoeur, 1999: 15-16); la segunda permite que el individuo pueda sentir una continuidad en esa identidad producida y, la tercera, posibilita la proyección de dicha continuidad del sujeto hacia al futuro. Sin embargo, esa identidad podría ser problemática si pensamos que se sustenta precisamente sobre un relato, sobre una construcción de algo que se aleja de la certeza de lo comprobable: el pasado. Un pasado que "parece presentarse como algo tan frágil que se desvanece ante lo que creíamos debería ser su conocimiento" (Brauer, 2002: 35). En otras palabras, como recreación, el pasado responde a la arbitrariedad de lo que recordamos y ese 
recordar es siempre variable porque, además, depende también de las condiciones del presente en el que está ubicado el sujeto del recuerdo:

Aunque, en efecto, los hechos son imborrables y no puede deshacerse lo que se ha hecho, ni hacer que lo que ha sucedido no suceda, el sentido de lo que pasó, por el contrario, no está fijado de una vez por todas. (...) Podemos considerar este fenómeno de la reinterpretación, tanto en el plano moral como en el del simple relato, como un caso de acción retroactiva de la intencionalidad del futuro sobre la aprehensión del pasado. (Ricoeur, 1999: 48-49).

La reinterpretación es lo que concede sentido a los hechos recordados y lo que hace que la memoria se reescriba cada vez de otro modo y pueda concebirse como relato. Como el signo lingüístico que está en lugar de la cosa, el recuerdo está en el lugar de lo acontecido. Referirnos al pasado, evocarlo desde el presente, implica reformular esos acontecimientos que ya no están. En palabras de Brauer: "Los hechos del pasado han desaparecido. Decimos que de algún modo 'se conservan' en nuestros recuerdos, con lo que queremos indicar no la presencia de ellos mismos sino de su imagen en nosotros" (Brauer, 2002: 47). Y esta imagen es la que se (re)interpreta cuando organizamos los recuerdos en el presente.

Explica Brauer que la percepción responde al presente y el recuerdo al pasado y, en la interrelación de estas dimensiones temporales, es posible la experiencia narrativa de la identidad. Nos fiamos de nuestros recuerdos porque éstos forman parte de una continuidad inseparable de la percepción y la proyección del futuro. $\mathrm{Al}$ respecto afirma Sara Makowski: "El sujeto es (...) siempre portador de memoria, una memoria que le precede y que es continuamente actualizada en el devenir individual. Se trata de una 'memoria actuante' en el discurso, en el quehacer y en el cuerpo del sujeto" (Makowski, 2002: 154). Desde una óptica parecida, Beatriz Sarlo explica que el pasado, al no poder ser eliminado, es un "perseguidor" que puede esclavizar o liberar y dependiendo de cómo se organice "mediante los procedimientos de la narración" será comprensible "su irrupción en el presente" (Sarlo, 2005: 13). La memoria depende de estrategias narrativas para articular el pasado en el presente y proyectarse al futuro. A la vez, esta narración del pasado que, como explica Sarlo, es un pasado del que se habla "sin suspender el presente y, muchas veces, implicando también el futuro" (ibídem.), funda la noción de sujeto o individuo, es decir, sustenta la identidad.

Ahora bien, esta estructura narrativa que caracteriza la memoria estuvo durante mucho tiempo instituida como un relato totalizador donde el sen- 
tido producido procuraba, o intentaba procurar, estabilidad mediante la idea de linealidad/continuidad. Es decir, se armaba el recuerdo de manera progresiva para formar un relato que daba la ilusión de contener un origen que proporcionaba a la sociedad, en general, y al individuo, en particular, una identidad "consolidada" en un entorno "seguro". Sin embargo, y como es sabido, esta certeza que brindaba el relato lineal ha sido cuestionada desde hace unas cuantas décadas y han quedado al descubierto aquellas costuras en las que se evidencian los quiebres y los silencios del pasado. Una oquedad que a su vez pone de manifiesto lo circunstancial de todo origen y, por tanto, la incertidumbre de cualquier continuidad "Histórica":

(...) si el genealogista se toma la molestia de escuchar la historia más que añadir fe a la metafísica, ¿qué descubre? Que detrás de las cosas hay "otra cosa bien distinta": no su secreto esencial y sin fecha, sino el secreto de que no tiene esencia, o de que su esencia fue construida pieza a pieza a partir de figuras extrañas a ellas (Foucault, 2004: 18).

Por ello, la manera de aproximarse al pasado ya no puede ser desde una intención totalizadora sino desde la convicción de que la línea narrativa del pasado está minada de discontinuidades.

La construcción de un relato de identidad -personal y familiar- mediante el cuestionamiento de la estabilidad del origen puede rastrearse, en buena medida, en el poemario Casa o lobo (1981) y en el segmento "Los hornos" de La épica del padre (2002) de Yolanda Pantin (Caracas, 1954).

Desde el primer poema de Casa o lobo la voz poética concibe la infancia no como edad dorada que se anhela y a la que no podemos volver, sino como imposibilidad que se acepta sin nostalgia, ya que existe el reconocimiento de que restaurar el pasado a partir de los ojos del adulto es algo ilusorio: La infancia es una gracia que me fue desprendida (Pantin, 2004: 11). La memoria de la infancia se plantea como evidencia de la imposibilidad de precisar el origen. Está desunida del sujeto que la recrea; desligada del presente de la voz poética. Es el recuerdo más lejano y sólo podemos referirnos a ella como observadores parciales, ajenos. Si bien es aquello que le permite a la voz poética construirse una identidad: Aquello que me viene me devuelve persona con brío de reír (Pantin, 2004: 11), es una identidad erigida sobre la conciencia de que esa memoria de la infancia no es un espacio fundacional 
inmutable sino, como plantea Manuel Cruz: “(...) la construcción de eso que somos (llámese identidad personal, biografía o de cualquier otra manera) no tiene un solemne momento fundacional, originario, del que la memoria pudiera constituirse garante y guardián al mismo tiempo" (Cruz, 2002: 16). La memoria de la voz lírica está truncada: Ya no tengo memoria para el nombre del árbol y semilla tallada (Pantin, 2004: 11) y, por lo mismo, no hay garantía o seguridad en la rememoración de dicho instante, sino, más bien, evidencia de que lo que puede desprenderse del recuerdo es inseguro y ficticio en cuanto es ficcional: Lo cierto, más oscuro (Pantin, 2004: 11). Simultáneamente, dicha memoria del pasado infantil es una memoria que se estructura desde dos posibilidades: el recuerdo del hablante lírico y el recuerdo de lo que le puedan contar los que eran adultos cuando la voz poética era una niña: Cuando divago y pregunto, háblame de aquello (Pantin, 2004: 11). Porque, como explica Brauer, una de las formas de confirmar los acontecimientos pasados es por "la vía intersubjetiva: comparar nuestros recuerdos con los de los demás” (Brauer, 2002: 47).

Este indagar de la voz poética, veremos, no es una búsqueda del origen fundacional capaz de brindar seguridad en cuanto a quién es o de dónde viene, sino una interrogante que evidencia la fragmentariedad e inestabilidad del relato de la evocación del pasado infantil y de ese mismo origen. Así, Pantin elabora una escritura que parte de una conciencia genealógica de su historia personal:

La historia, genealógicamente dirigida, no tiene por meta encontrar las raíces de nuestra identidad, sino, al contrario, empeñarse en disiparlas; no intenta descubrir el hogar único del que venimos, esa patria primera a la que los metafísicos prometen que regresaremos; intenta hacer aparecer todas las discontinuidades que nos atraviesan (Foucault, 2004: 68).

Lo que pone en escena Yolanda Pantin, según la lectura que de la genealogía hace Foucault, es la discontinuidad que franquea su pasado personal y que empaña las raíces de la identidad.

Una imagen recurrente en ambos poemarios es la casa. Sin embargo, no es la casa que, simbólicamente, se compone de la sabiduría y por lo tanto representa las propias tradiciones, sino una casa que deconstruye las tradiciones familiares. La casa de la infancia en Turmero no es una referencia nostálgica a la casa que podría significar el origen, la tradición como sostén y seguridad garantizada al reconocerlo, sino, por el contrario, una alusión constante al miedo. En Casa o lobo leemos: (...) Siempre, siempre, había en los pasillos, en los corredores, en cada una de las columnas, había en el zaguán 
un miedo acongojado (Pantin, 2004: 12). Esta casa que parece surgir del recuerdo de la voz poética como memoria involuntaria: Esta casa surge despacio en el agua de la lluvia que caía por los muros y olía a yerba y a todo eso, (Pantin, 2004: 11) es la representación del recuerdo del miedo del niño ante el mundo de los adultos y, también, del reconocimiento del espacio infantil como aquello que ha quedado "desprendido" de la percepción adulta del yo lírico, de su presente: Nos entran por los ojos letanías cuando de noche relucen candelabros, la mesa y la plata dispuestas, ellos tan vestidos y uno en la puerta rogando de la lluvia por afuera de los muros, la cal y los espejos (Pantin, 2004: 12). Se confirma en estos versos la lectura que hace Sara Makowski de Vicent de Gaulejac a propósito de pensar la memoria también como una herencia en cuanto ésta equivale a un inventario de: "sentidos, emociones, fantasmas, secretos y lealtades que preceden al individuo, con la cual tendrá que refundarse para encontrar entre esos materiales -con ellos o contra ellossu propio proyecto, su lugar en el mundo" (Makowski, 2002: 154).

Una vez más, la identidad se establece en un confluir de discontinuidades: En esta casa se amontonan los fantasmas (Pantin, 2004: 12). La palabra fantasma, proveniente del latín phantasia, significa 'aparición, espectáculo, imagen' (Corominas, 1994: 267) y en este sentido se relaciona con la noción de recuerdo, en cuanto imagen que está en lugar de lo ausente y que no puede sino volver. La naturaleza del fantasma es particular en cuanto se percibe como si estuvieran regresando, cuando en realidad nunca estuvo. Es siempre imagen de una ausencia y, en los versos de Yolanda Pantin, los fantasmas parecen tener una doble función: actúan como representación en cuanto están nombrando algo que ya no está y, simultáneamente, cuestionan la "transparencia" de la herencia familiar:

(...) Irrumpen en los muros las cavernas y se espantan. Uno destila de abrir huecos y piensa, estático, benigno, a esa cueva le pesan los estribos, los bronces, las cosas aquellas puntiagudas de tanto escondidas, de tanto embrujadas, de tanto aparecer y desaparecer como si cualquier cosa todos los días (Pantin, 2004: 12).

La casa es sustituida aquí por la cueva. La tradición cede paso, entonces, a lo que tradicionalmente suele simbolizar la caverna: "lo continente, lo cerrado, lo oculto" (Cirlot, 1998: 129). De esta forma, sus paredes, constituidas por la herencia familiar, se hacen pesadas. La tradición no es lo que aporta las certezas, sino la carga del secreto.

En el poema que sigue leemos: Aparecen ellos de tanto siglo en las espaldas (Pantin, 2004: 12). La mención a los siglos parece aludir a esa herencia a la 
que se refiere Makowski. La herencia-inventario que la voz poética intenta reconstruir desde su cama: Se recuestan en mi cama (Pantin, 2004: 12). Simultáneamente, estos versos parecen una puesta en escena de cómo esta voz poética recuerda:

Se siente en el aire de la casa un vaivén de hamaca desaparecida. Uno persigue de la sala hasta el patio el eco de la risa, el rebote en las paredes, las ganas contenidas de abrazarlos e hincárseles de rodillas, tan señores (Pantin, 2004: 12).

Se entiende a partir de estos versos cómo la memoria no es concebida como repetición de lo ausente sino como un proceso con el que se lleva a cabo la rememoración. Así, estos versos pueden relacionarse o pensarse a partir de la reflexión de Daniel Brauer sobre la retrospectiva:

La palabra "retrospectiva" (...) proviene de una metáfora espacial e indica un mirar hacia atrás. Su antónimo es la "prospectiva" o sea un mirar hacia delante con el que nos referimos al futuro. (...) La retrospectiva misma, en tanto un "pasar revista" que puede moverse en ambas direcciones del antes y el después, no debe identificarse con la memoria como tal, o en todo caso deben diferenciarse en ella 1) el recuerdo (como imagen, o secuencia de imágenes) de 2) la evocación (como facultad de despertar las imágenes) y de 3) la reflexión retrospectiva (que consiste en un proceso de comparación, puesta en orden e interpretación de los recuerdos) (Brauer, 2002: 49-50).

La imagen de la hamaca desaparecida desde este enfoque puede pensarse como el recuerdo, como aquello que viene al presente pero que ya no está. Ha desaparecido en cuanto objeto físico y sólo nos queda una imagen. El segundo verso no alude al recuerdo pasivo o la imagen que viene como la de los primeros fantasmas que se recuestan en su cama, sino por la (re) construcción que el yo lírico hace. El hablante poético persigue las risas. Trata de alcanzarlas pero no puede. Sólo son eco; es decir, un vago rastro que queda de algo que fue pero que ya no es ni puede ser y que se percibe débilmente, de la misma manera como sólo puede ser el relato de la memoria.

Por último, el recuerdo y la evocación confluyen en la reflexión retrospectiva: Le entran a uno deseos de irse entre los muros, pegado a las paredes: la cal y el polvo siguiendo huellas hasta los hornos altísimos. Más nunca abrirán troneras de tantas aldabas en las puertas del patio (12). El adverbio "nunca" nos permite aventurarnos a afirmar que la voz poética tiene conciencia de que la memoria es relato y, por tanto, se haya construyendo sus recuerdos. Así, pareciera que el sujeto poético se haya reflexionando sobre el funciona- 
miento de su propia memoria. Hay una conciencia de que esas imágenes son sólo eso, imágenes y no hay manera de volver a ellas. Lo que percibimos como volver a ellas al momento de recordar es en realidad una constante primera vez, porque lo que se construye cuando uno vuelve atrás no estaba antes, es el producto de la relación presente-pasado, de una demanda del presente que desencadena una (re)lectura del pasado.

Por otro lado, la casa no es sólo la imagen o el recuerdo de ese lugar en el que la voz poética pasó su infancia, es también metáfora de cómo el recuerdo y la evocación producen la reflexión retrospectiva: Largos corredores me cercan (Pantin, 2004: 13), dice el yo poético. Los corredores que circundan al yo lírico actúan como el recuerdo que emerge y confronta al sujeto para permitirle forjar su identidad. Una identidad sustentada en la herencia familiar entendida como stock que le permite al sujeto fundar su propio proyecto, en este caso específico, a partir del rechazo de los elementos que la conforman: Oscura certeza de mirarme en el fondo (Pantin, 2004: 13). Y, desde este enfrentamiento, reconocer una herencia y un origen problemáticos.

(...) esa herencia no es una adquisición, un haber que se acumule y se solidifique; más bien es un conjunto de fallas, de fisuras, de capas heterogéneas que la vuelven inestable y que, desde el interior o desde abajo, amenazan al frágil heredero (Foucault, 2004: 28).

Ese heredero amenazado, esa identidad fragmentada, se testimonia a partir del relato del pasado de la voz poética:

El último cuarto del pasillo donde una figura crece y multiplica. El de antes niño o sabio de palabras se cruza la cara con barro. Un hombre lo hiere, persigue a salto de bestia. Levanto a ratos persianas: afuera es un vértigo con rigor de espejo (Pantin, 2004: 13).

La evocación del pasado le devuelve al yo poético su imagen. Una imagen múltiple que da vértigo, que es un origen incapaz de proporcionar seguridad: Me sobrevive el más cerca. El que tiene mi nombre y juega a morir como un zarpazo hacia dentro (Pantin, 2004: 13). La retrospección, además, se vuelve introspección -zarpazo hacia dentro-y permite reconocer el abismo insalvable entre el adulto del presente y el niño-imagen que perturba como los fantasmas. El fantasma de la infancia que ya no es posible experimentar sino como la presencia de una ausencia que perturba el presente: habránse visto niños de estatura muy quieta, de piernas cruzadas, el pequeño animal, lobo de siempre, en el ojo que brilla (Pantin, 2004: 13). La imagen del yo lírico, como heredera de ese "conjunto de fallas" se relaciona con el lobo. 
Primera alusión al título del poemario y que parece indicar ese juego reflexivo entre la casa, sinónimo de seguridades y el lobo que, en la tradición simbólica, aparece como guardián. Se desordenan las significaciones: la casa es incapaz de resguardar de los temores y el lobo es el animal que inspira miedo, el de los cuentos de hadas que se come a su víctima y no la loba madre que protege a Rómulo y Remo.

En otras palabras, en la construcción Casa o lobo hay una duda explícita que se representa en estas dos figuras y que pueden interpretarse como esas capas variadas a las que hace referencia Foucault y que, aquí, se presentan como inestabilidad: "La búsqueda de la procedencia no fundamenta, al contrario: agita lo que se percibía inmóvil, fragmenta lo que se pensaba unido; muestra la heterogeneidad de lo que imaginábamos conforme así mismo" (Foucault, 2004: 29). La mirada retrospectiva funda la incertidumbre que en los versos de Pantin se anuncia como oscuridad de donde los recuerdos emergen como débiles evocaciones: Sitio oscuro donde salen de noche los fuegos fatuos (Pantin, 2004: 13). Y, sin embargo, podríamos pensar que hay una necesidad del yo poético por fingir una identidad homogénea, por esconder la certeza de lo heterogéneo: Llegamos contando gracias. Disimulando (Pantin, 2004: 13). ¿Para soportar la identidad es necesario disfrazar la pluralidad de la herencia memorística? ¿Disimularla, hacer que parezca algo distinto: homogéneo, uniforme? O quizás ¿este disimulo es una crítica a quienes quieren ver en la herencia memorística un origen certero?

La lectura de otros versos puede hacer que una respuesta afirmativa surja de la última interrogante. En los poemas de Yolanda Pantin no predomina el engaño o la necesidad de creer que hay un origen uniforme sobre el cual podemos volver cuando nos haga falta y que nos procura una identidad estable, fija: Las personas, como algunas, son ovillos de sí mismas recogidas del viento. Habitan las casas más profundas (Pantin, 2004: 16). La persona asociada con el desorden o el enredo en forma circular-ovillos- nos invita a pensar en una identidad compleja y la "casa profunda" tiene relación con la casa-caverna o casa-cueva de los versos anteriores que está lejos de ser ese refugio de la memoria uniforme y estable.

Esta inseguridad que subyace en el origen se ve también referida desde la herencia memorística que no hace otra cosa que minar los basamentos de la identidad: Cada uno tendrá su propia raíz bajo el cuello. Y cada quien tenderá su mano al bajar la cabeza (Pantin, 2004: 16). Cada uno tendrá su propia identidad -raíz-fundada en los recuerdos heredados que siempre son, como argumenta Ricoeur a propósito de la memoria personal, singulares y, por lo tanto, consolidan un origen que: "lejos de ser una categoría de la semejanza, (...) permite separar, para ponerlas aparte, todas las marcas diferentes 
(Foucault, 2004: 29). Por ello, en el reconocimiento de las desviaciones, el yo se afirma como entidad perdida en esas divergencias: A veces padecemos como hojas pequeñas y la palabra amor se me antoja línea de escupir (Pantin, 2004: 16). Esa hoja que podemos imaginar perdida o ignorada entre miles de otras, ¿la persona dentro de esta herencia familiar de vivos y muertos, de evocaciones del pasado y percepciones en el presente?, se reconoce sola: Porque uno se está sólo y la piedra donde existo es mi vasto territorio. En este roce Dios es el hueco de gastarnos. Porque uno está solo en el lugar o estancia o salto de pie en el vacío (Pantin, 2004: 16). Esto, junto a la referencia a un Dios-podría decirse certeza- vacío, nos invitan a pensar en esa identidad que se enfrenta a los elementos de la memoria y se descubre no sólo escindida sino abandonada dentro de dicha herencia, perdida ante el reconocimiento de la fragilidad de dicho legado.

\section{III}

Por otro lado, la memoria como relato que se articula a partir de la reflexión retrospectiva puede concebirse como una escritura en tanto ordenación e interpretación de los recuerdos, así como por el hecho de que toda memoria implica necesariamente una selección.

(...) hay que recordar algo evidente: que la memoria no se opone en absoluto al olvido. Los dos términos para contrastar son la supresión (el olvido) y la conservación; la memoria es, en todo momento, una interacción de ambos. El restablecimiento integral del pasado es algo por supuesto imposible (...) y, por otra parte, espantoso; la memoria, como tal, es forzosamente una selección: algunos rasgos del suceso serán conservados, otros inmediata o progresivamente marginados (Todorov, 2000: $16)$.

De esta exigencia selectiva que distingue Todorov se desprende que la memoria puede pensarse como reconstrucción. En este sentido, dicha recuperación del pasado termina siendo, desde la voz poética de los versos de Yolanda Pantin, una producción consciente que se enuncia desde y solo por la escritura. La memoria es un invento en cuanto descubrimiento de la imagen que es el recuerdo: Invento un pajonal salido de todas partes (Pantin, 2004: 13). En otro poema se lee: Hacemos nombres (Pantin, 2004: 14). La elección de los verbos pone de manifiesto que la voz poética está consciente de que está construyendo el relato de su memoria y que toda memoria es creativa en cuanto objeto reencontrado que se produce en la confluencia de 
la imagen y la interpretación de dicha imagen en el momento que es retomada por la voz poética desde el presente.

La memoria como escritura puede también argumentarse si nos aproximamos a "Los hornos" de La épica del padre a partir de la hipótesis de que es una re-escritura de Casa o lobo. En consecuencia, como una relectura de la memoria infantil de la voz poética encontramos que la identidad de dicha voz se define como narración de la experiencia de lo que ha sido y, por tanto, como registro que varía según el lugar de enunciación desde donde se encuentra el yo lírico. Explica Sarlo que "la narración inscribe la experiencia en una temporalidad que no es la de su acontecer (amenazado desde su mismo comienzo por el paso del tiempo y lo irrepetible), sino la de su recuerdo" (Sarlo, 2005: 29) y, además, da paso a una temporalidad que se actualiza en las repeticiones. Desde esta perspectiva, una vez más reconocemos una voz poética que evidencia el acto de recordar: son las imágenes traídas (Pantin, 2002:17). La retrospectiva de la niñez, nuevamente, está enmarcada por recuerdos que evocan el temor: Esta mañana recordé a las lechuzas que habian mudado sus nidos a lo alto de los hornos, al lado de la casa. Los niños abríamos la puerta con temor y allí estaban (...) (Pantin, 2002: 17). La casa aparece unas veces como pura imagen, es decir, pura descripción: La casa se abría como una ele hechizada al jardín lujoso, la casa de muebles austeros, parca, semejante a una persona contenida (...) (18) y otras, a partir de la relectura, como una actualización de la casa-cueva de Casa o lobo: No era una casa, era una atmósfera asfixiada (18).

La relectura hecha por la voz poética del estadio infantil en "Los hornos" aparece la distinción de dos casas, la de los niños y la de los adultos, que no aparece en la evocación de la casa de Casa o lobo: No vivían los niños en la Casa Grande de los abuelos, vivían en la Casa Pequeña, con los otros niños, donde el vientre de la madre crecía hasta que lloraba la criatura en la cuna a su lado (Pantin, 2002: 20). Dos espacios reconocidos por la evocación que funcionan significativamente gracias a la mirada retrospectiva y que forman una dialéctica interesante. En la reescritura memorial la imagen de la casa se actualiza. De esta forma, se refuerza la significación del espacio de la infancia frente al espacio de la adultez.

Una imagen recurrente en ambos textos es la de los murciélagos: También Dios mudaba escaparates en el cuarto de al lado de techo enorme con murciélagos y todo (Pantin, 2004: 12). En el universo infantil, el murciélago no inspira temor: Los murciélagos volaban con sedosa humildad. El invisible vuelo de los murciélagos en la noche (Pantin, 2002:17). Sin embargo, cuando están relacionados con la Casa Grande, léase el mundo adulto, la significación se modifica y se carga de un sentido, otro, relacionado con lo inquie-

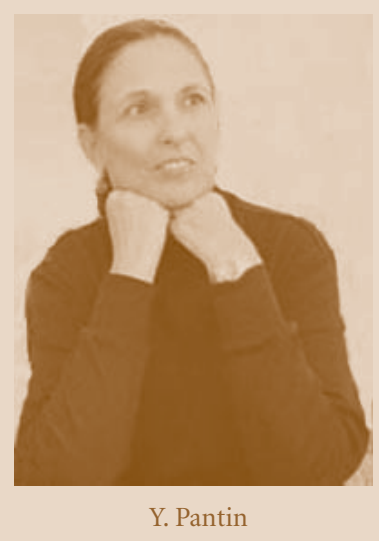

Y. Pantin 
tante, con el temor: Son los días del miedo. Y las noches largas, parpadeo de las aves nocturnas (Pantin, 2002: 20).

Por otro lado, la reflexión sobre una infancia desmitificada en cuanto origen estable, que es incapaz de proveer seguridad alguna ya que es un estadio inaccesible una vez que la voz poética se reconoce adulta, se halla representada, si se quiere, de una forma más diáfana en este segmento de $L a$ épica del padre: Luego se olvidaron. Pero lo extraño se hundió en el corazón de las criaturas y se deslizó en la suave extensión de los potreros, (...) (Pantin, 2002: 22). Queda la huella de la experiencia. Una experiencia que, como señala Sarlo, puede entenderse como: "lo que puede ser puesto en relato, algo vivido que no solo se padece sino que se transmite" (Sarlo, 2005:31) y que es metanarración cuando se actualiza mediante la escritura. El olvido se entiende como parte de la memoria y es revelador de algo que no se quiere decir, saber. El "olvido" perturba en silencio y se instala en un espacio sombrío que nos remite a la transición de la niñez a la adultez, una vez más, representada por la casa: en el callejón que comunicaba a la Casa Pequeña con la Casa Grande (22). Y, además, un olvido que revela la problemática experiencial que plantea Le Goff y que Sarlo describe como una incomunicabilidad que es consecuencia de una crisis entre "la autoridad del pasado sobre el presente" (Sarlo, 2005: 31): La razón del extravío, pensaban los niños, fue haber descubierto el infierno en el cielo, el lugar donde el sol en la tarde se esconde $y$ arde en llamas de un rojo encendido (Pantin, 2002: 22). La reescritura le permite a la voz poética tomar conciencia de la ruptura entre la autoridad del pasado y los herederos de la tradición.

En esta relectura se actualiza, se pone al día, la conciencia de la escisión entre el mundo adulto y la niñez a partir de la forma de aproximarse a cada uno de los estadios. En Casa o lobo los adultos son evocados como figuras que causan en los niños una sensación de desamparo:

Vienen con sombreros de copa. (...) Vendrán a visitarnos ricos parientes. (...) De uno en uno, aparecidos, nos presentan exclamando, he aquí a mi hijo el mayor y siguientes. Las muchas criaturas se yerguen violentas. Sudan por encima del hombre. Limpian el rostro de madera y se vuelven en honor como dioses desprovistos (Pantin, 2004:15).

En "Los hornos" el espacio adulto se actualiza y se convierte en la dimensión del temor. Construcción de una imagen del adulto frente a la que la del niño se paraliza:

(...) Los niños callados en el aula de clases del colegio Carmelo, dibujando por mandato de la monja un paisaje que sorprende por la minuciosi- 
dad de sus detalles, (...) El ciego, el distraído, el sordo de los niños, levanta la mano de la mesa. No, dice la Hermana, ¿no fuiste en el recreo? El niño parado de pie ante la clase se orina como ha visto hacerlo a los potrillos que entran en el jardín, mojado, con las medias mojadas, como un bebé (Pantin, 2002: 22).

La remembranza de la infancia, cuando hay encuentro con los adultos, es una experiencia traumática en cuanto constituye una tensión entre el mundo del adulto y el del niño, un contraste entre: el orden exigido (Pantin, 2002: 22) y El paisaje ensimismado jamás puesto en duda por ninguno de los niños (Pantin, 2002: 21). Hay en esta relectura del espacio infantil un reconocimiento de la imposibilidad de volver a ese espacio con los ojos de niño que actualiza dicho espacio a partir de la fractura infranqueable que se reconoce desde el relato de lo que es la identidad del adulto.

Lo que se desprende de esta breve lectura de los textos de Yolanda Pantin es que la voz poética no se detiene sólo en el recuerdo entendido como imágenes fragmentadas que vienen por la evocación: Las torres de los hornos, los conejos. Sonata, Sonatina. El tanque llamado 'la piscina', de aguas verdes (Pantin, 2002: 18), sino que dichas imágenes se articulan gracias a la mirada retrospectiva que genera un relato reflexivo y memorial. En estos versos no sólo leemos la reconstrucción de la historia personal del yo lírico, sino que éstos se encuentran escenificando el funcionamiento de la memoria.

Ante esto, cada poema de Casa o lobo y de "Los hornos" de La épica del padre evidencia que el sentido de lo recordado depende del momento de la percepción del presente desde donde se recuerda. Así, la voz poética construye el relato de su identidad desde la conciencia de que le pregunta por el pasado no puede hacerse con la esperanza de una reconstrucción homogénea capaz de delimitar un origen transparente y sosegado, sino que, por el contrario, dicho origen es problematizado desde el momento que se reconocen las discontinuidades que lo conforman.

Simultáneamente, la conciencia de este origen discontinuo permite al lector que se aproxima a estos versos reconocer que la memoria es representación, escritura que reelabora aquello que ya no está. Por tanto, en su reelaboración no puede haber confianza en cuanto al origen y, mucho menos, continuidad de la identidad.

Por último, en los versos de esta autora, la escritura de la infancia, que se realiza desde esta conciencia interpretativa del relato del pasado, pone de manifiesto que entre el universo de la infancia y la identidad adulta existe una escisión insalvable. Una ruptura que, desde la reconstrucción del relato, describe lo que, en la reelaboración, la voz poética considera que el niño enfrenta frente al adulto. Además, la voz poética mediante la escritura revela 
que los ojos del adulto sólo pueden observar la infancia desde el límite que bordea la ruptura entre el estadio infantil y el adulto. Los versos de Yolanda Pantin ponen en claro que el recuerdo de la infancia sólo puede entenderse como un proceso en proceso, como un discurso siempre en construcción y, por lo mismo, como un relato que podemos estructurar desde el presente, mas no como un estadio al que se puede regresar para buscar un origen que le procure una continuidad a la identidad del adulto.

\section{REFERENCIAS}

Amado, Ana y Domínguez, Nora (Comp.). 2004. Lazos de familia. Herencias, cuerpos y ficciones, $1^{\text {a }}$ edic. Barcelona, España: Paidós.

Brauer, Daniel. 2002. "La fragilidad del pasado", en: Cruz, Manuel (Comp.), Hacia dónde va el pasado. Bs. Ars., Argentina: Paidós.

Corominas, Joan. 1994. Breve diccionario etimológico de la lengua castellana, $3^{\mathrm{a}}$ edic. Madrid, España: Editorial Gredos.

Cirlot, Juan Eduardo. 1998. Diccionario de símbolos. Barcelona: Siruela.

Cruz, Manuel (Comp.). 2002. Hacia dónde va el pasado. Buenos. Aires, Argentina: Paidós.

Foucault, Michel. 2004. Nietzsche, La genealogía, la historia. Valencia: Editorial Pre-textos.

Makowski, Sara. 2002. "Entre la bruma de la memoria. Trauma, sujeto y narración". Perfiles Latinoamericanos. Revista de la Facultad Latinoamericana de Ciencias Sociales, diciembre, No 21.

Pantin, Yolanda. 2002. La épica del padre. Caracas, Venezuela: La nave va.

-2004. Casa o lobo. En: Poesía reunida 1981-2002. Caracas, Venezuela: Editorial CEC.

Ricoeur, Paul. 1999. La lectura del tiempo pasado: memoria y olvido. Madrid: Arrecife/Universidad Autónoma de Madrid.

Sarlo, Beatriz. 2005. Tiempo pasado. Cultura de la memoria y giro subjetivo. Una discusión. Bs. Ars., Argentina: Siglo Veintiuno editores.

Todorov, Tzvetan. 2000. Los abusos de la memoria. Barcelona, España: Paidós. 